\title{
INFLUENCE OF GENDER ON PAIN, QUALITY OF LIFE, AND PHYSICAL ACTIVITY IN PATIENTS WITH KNEE OSTEOARTHRITIS
}

\author{
Tan Xue Min, Vinosh Kumar Purushothaman, Yughdtheswari Muniandy*
}

INTI International University, Faculty of Health Sciences, Physiotherapy program, Persiaran Perdana BBN, Putra Nilai, 71800 Nilai, Negeri Sembilan, Malaysia

Received - July 18, 2020; Revision - September 17, 2020; Accepted - December 08, 2020

Available Online - March 25, 2021

DOI: http://dx.doi.org/10.18006/2021.9(Spl-1-GCSGD_2020).S139.S147

\section{Keywords \\ Pain \\ Knee osteoarthritis \\ Physical activity \\ Quality of life}

\begin{abstract}
Osteoarthritis is the most common cause of knee pain which contributes to adults' disability. Females have an increased risk of knee osteoarthritis. However, little is known about the gender influence in pain perception, quality of life (QOL), and physical activity. Hence, this study aimed to investigate the influence of gender on pain perception, QOL, and physical activity in patients with knee osteoarthritis. A cross-sectional study design with a total of 186 patients(mean age of $56.64 \pm 6.49$ ) with knee osteoarthritis were recruited. Pain intensity, level of physical activity, and QOL of patients were assessed using a visual analog scale (VAS), global physical activity questionnaire (GPAQ), and Short Form-36 (SF-36) questionnaire. Among the studied patients, 52\% of patients with knee osteoarthritis had a relatively low level of physical activity with females representing the majority of them. Lower mean was observed in QOL and physical activity whereas pain intensity was higher in females compared to males $(\mathrm{p}<0.05)$. Pearson correlation demonstrated a strong negative correlation between physical activity and pain $(\mathrm{r}=-0.77, \mathrm{n}=186, \mathrm{p}<0.01)$, and a weak correlation exist between physical activity and all domains of QOL except for the functional capacity and body pain. Majority of female participants with knee osteoarthritis exhibit poor QOL, physical activity, and increased pain intensity as compared to males. Clinicians need to be aware of the influence of gender in treating patients with knee osteoarthritis.
\end{abstract}

* Corresponding author

E-mail: eshwari_physiorehab@yahoo.com (Yughdtheswari Muniandy)

Peer review under responsibility of Journal of Experimental Biology and Agricultural Sciences.

Production and Hosting by Horizon Publisher India [HPI] (http://www.horizonpublisherindia.in/).

All rights reserved.
All the articles published by Journal of Experimental Biology and Agricultural Sciences are licensed under a Creative Commons Attribution-NonCommercial 4.0 International License Based on a work at www.jebas.org.

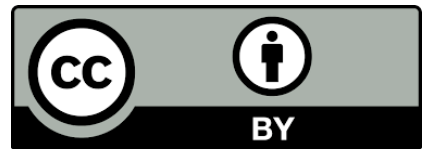




\section{Introduction}

Osteoarthritis is the most widespread chronic degenerative musculoskeletal disease, leads to pain and physical disability in adult individuals (Alenazi et al., 2020). It is a disease that progresses over time in joints causing significant changes in the tissue architecture, its metabolism, and function (Primorac et al., 2020). It commonly affects the joints in the hands and weightbearing joints including knees, hips, feet, and spine (Chinese Orthopaedic Association, 2010). There were approximately 8.5 million adults in the UK and 27 million US adults have clinical osteoarthritis (Dillon et al., 2006).

The primary burden of osteoarthritis is pain and physical impairments which significantly influence the quality of life (QOL) of individuals (Elliott et al., 2007; Boutron et al., 2008; Yildiz et al., 2010). Several risk factors such as pain, inaccuracy proprioception, and muscle weakness have been identified in the declination of physical function in osteoarthritis patients (Dunlop et al., 2005; Dekker et al., 2009). Studies have reported that lack of regular physical activity is one of the most predominant risk factors in deteriorating the functions of activities of daily living (ADL) in patients with osteoarthritis (Dunlop et al., 2010). It can be interpreted as a pattern of avoidance for certain patients with osteoarthritis who are likely to delay physical activity in fear of escalating pain in the injured joint (Steultjens et al., 2002; Somers et al., 2009).

Apart from the pain and functional limitation, osteoarthritis also affects an individual's psychological well-being which negatively affects the quality of life (Elizabeth \& Rena, 2011; Sharma et al., 2016). Female gender is a major predisposing factor of knee osteoarthritis (Ferre et al., 2019). There is a dearth of research in this field, in which the effects of gender on pain severity, quality of life, and physical activity is uncertain. Therefore, the present studies aim to identify the influence of gender on pain, quality of life, and physical activity in patients with knee osteoarthritis and determining the relationship of physical activity with pain and quality of life.

\section{Materials and Methods}

A cross sectional study using the convenience sampling method was adopted. For this analysis 186 participants were recruited. The inclusion criteria were participants between the age of 40 to 60 years, who have been diagnosed with knee osteoarthritis and presented with complaints of knee pain for the past 6 months or more. Whereas, the exclusion criteria included participants with a known history of a traumatic knee injury, undergone knee replacement surgery, rheumatoid arthritis, central or peripheral nervous system disorder, or a condition that limits pre-mobility

Journal of Experimental Biology and Agricultural Sciences http://www.jebas.org status. Before collecting data, all participants were provided details about the intent and procedure of research, and written informed consent was taken. This study was approved by the Research and Ethics Committee of INTI International University.

All the eligible participants were given a form to fill that comprised of demographic details such as age, gender, occupation, level of physical activity, and pain assessment chart. The participants were screened for pain using the Visual Analog Scale (VAS). It is a $10 \mathrm{~cm}$ continuous scale with one end representing the maximum intensity and the other end of no pain (Crichton 2001; Kahl \& Cleland 2005). Participants were asked to measure their pain level at rest and during activity. The greatest benefits of VAS are the simplicity of its design and usage. Besides that, VAS is highly reliable with an intraclass correlation coefficient (ICC) between 0.71 to 0.99 (Kahl \& Cleland 2005).

Meanwhile, a global physical activity questionnaire (GPAQ) was used to assess the level of physical activity. It includes 16 questionnaires to identify physical activity at work, travel to and from places, and recreational activities. The physical activity level of each participant was measured using the metabolic equivalent of task-minute per week by combining the score of work, travel, and recreational MET-minutes/week (Herrmann et al., 2013). Participants were categorized into 3 levels, high > 6.0 MET-min/ week; moderate between 3.0 to $6.0 \mathrm{MET}-\mathrm{min} /$ week; and low below < 3.0 MET-min/ week (Bull et al., 2009). The QPAQ is found to be valid and reliable which demonstrated moderate to strong positive relationships ranging between 0.45 to 0.65 (Bull et al., 2009).

Short Form-36 (SF-36) was used for the assessment of the quality of life (Ware, 2000). It is a 36 item questionnaire that has been divided into 8 domains including physical functioning (10 elements), social functioning ( 2 elements), role limitations due to physical health (4 elements), role limitation due to emotional problems (3 elements), mental health (5 elements), energy and vitality (4 elements), bodily pain ( 2 elements) and general health (5 elements). Each item is recorded on a scale with values from 0 to 100 which corresponds to the worst and best health status respectively. Aggregate scores were compiled into a percentage. A greater score indicates better QOL (Ware Jr \& John, 2000; Salaffi et al., 2005; Alkan et al., 2014). Each item has to carry equal weight. The SF-36 demonstrated high internal consistency (Cronbach's alpha ranged from 0.65 to 0.94 ) and excellent reliability (ICC between 0.75 t0 0.97) (Heyland et al., 2000). Statistical software package SPSS (Version 25.0) was used to interpret data. The Kolmogorov-Smirnov test, Q-Q plot, and skewness ranging between -1 to 1 was used to check the assumption of normality. The T-test was used for the assessment of the mean of the two groups. The correlation between physical 
activity and other factors were tested using Spearman's correlation analysis. The findings were defined at a confidence level of $95 \%$ with a significant level at $\mathrm{p}<0.05$.

\section{RESULTS}

Total 186 participants (91 males 95 females) were recruited with a mean age of $56.64 \pm 6.49$. The sociodemographic data of participants with knee osteoarthritis are as depicted in Table 1. The highest percentage of participants were between the ages of 50 to 59 years, with most of them were Malay. Most of the participants complain of moderate-intensity (between 5 to 7 ) pain $65.6 \%$, followed by mild intensity (between 1 to 4 ) of pain $28 \%$ and $6.5 \%$ with severe pain intensity (between 8 to 10 ).

\subsection{Level of Physical Activity in Knee Osteoarthritis}

This study demonstrated that almost more than half of participants $(52 \%)$, presented with a low level of physical activity $(<3.0$ MET -min/week), followed by $44 \%$ of participants with moderate physical activity (3.0 to 6.0 MET-min/ week) and $8 \%$ of participants with a high level of physical activity (> 6.0 MET$\mathrm{min} /$ week). The mean score of the total GPAQ in MET-min per week was $936 \pm 593$ for males and $598 \pm 265$ for females with the highest mean in the work domain followed by recreation and transport as depicted in table 2. There is significant difference among genders for all the physical activity domain ( $\mathrm{p}$ value < 0.001).

Table 1 Demographic characteristics of the participant with knee osteoarthritis

\begin{tabular}{|c|c|}
\hline Variables & $\begin{array}{c}\text { Participants }(\mathrm{n}=186) \\
\mathrm{n}(\%)\end{array}$ \\
\hline Age $($ mean \pm SD $)$ & $56.64 \pm 6.49$ \\
\hline \multicolumn{2}{|l|}{ Age Range } \\
\hline $40-49$ & $33(17.7)$ \\
\hline $50-59$ & $79(42.5)$ \\
\hline$\geq 60$ & $74(39.8)$ \\
\hline \multicolumn{2}{|l|}{ Gender } \\
\hline Male & 91(48.9) \\
\hline Female & $95(51.1)$ \\
\hline \multicolumn{2}{|l|}{ Ethnicity } \\
\hline Malay & $131(70.4)$ \\
\hline Chinese & $41(22.0)$ \\
\hline Indian & $13(7.0)$ \\
\hline Others & $1(0.5)$ \\
\hline $\begin{array}{l}\text { Pain intensity (mean } \pm \text { SD) } \\
\text { Pain intensity range }\end{array}$ & $52.20 \pm 15.05$ \\
\hline Mild (1 to 4) & $52(28.0)$ \\
\hline Moderate (5 to 7 ) & $122(65.6)$ \\
\hline Severe ( 8 to 10$)$ & $12(6.5)$ \\
\hline
\end{tabular}

According to the SF-36 in measuring the QOL, the mental health domain achieves the maximal value for both males and females with mean $+\mathrm{SD}$ of $72.7 \pm 7.6$ and $70.3 \pm 7.4$ respectively, while the lowest domain in males is for general health status with a mean + SD of $42.9 \pm 8.6$ and functional limitation domain in females with mean + SD of $37.7 \pm 16.7$.
Table 4 demonstrate statistical significant difference observed for functional capacity, $p=0.019$, functional limitation, $p=0.004$, bodily pain, $\mathrm{p}<0.001$, general health status 0.048 and mental health, $\mathrm{p}=0.029$. Examination of the mean scores indicates that there was remarkable QOL achieved for all the variables in males as compared to the females.

Journal of Experimental Biology and Agricultural Sciences http://www.jebas.org 
Table 2 Physical activity level of participants with knee osteoarthritis

\begin{tabular}{|c|c|c|c|}
\hline Physical activity domain & Male $(n=91)$ & Female $(n=95)$ & Significant value \\
\hline (MET-Min per week) & Mean \pm SD & Mean \pm SD & $\mathrm{p}$ \\
\hline Work & $685 \pm 685$ & $478 \pm 315$ & $<0.001$ \\
\hline Transport & $24.1 \pm 102$ & $16 \pm 66$ & $<0.001$ \\
\hline Recreation & $226 \pm 222$ & $104 \pm 150$ & $<0.001$ \\
\hline Total GPAQ & $936 \pm 593$ & $598 \pm 265$ & $<0.001$ \\
\hline
\end{tabular}

Table 3 Participants who did not met recommended physical activity level according to age

\begin{tabular}{|c|c|c|c|}
\hline \multirow{2}{*}{ Age (Year $)$} & Male $(\mathrm{n}=38) \mathrm{n}(\%)$ & $3(21.4)$ & Female $(\mathrm{n}=58) \mathrm{n}(\%)$ \\
\hline $40-49$ & $1(5.3)$ & $22(50.0)$ & $30(16.1)$ \\
\hline $50-59$ & $8(22.9)$ & $33(89.2)$ & $62(33.0)$ \\
\hline$\geq 60$ & $29(78.4)$ & $58(61.1)$ & $96(51.6)$ \\
\hline Total & $38(41.8)$ & & $\mathrm{n}(\%)$ \\
\hline
\end{tabular}

Table 4 Comparison of SF-36 score between gender among participants with knee osteoarthritis

\begin{tabular}{|l|l|l|l|}
\hline \multicolumn{1}{|c|}{ Quality of life domains } & \multicolumn{1}{c}{ Mean \pm SD } \\
\multicolumn{2}{|c|}{ Memale $(\mathrm{n}=95)$} & Significant value \\
\hline Functional Capacity & $52.2 \pm 17.6$ & $46.7 \pm 14.0$ & $0.019^{*}$ \\
\hline Functional Limitation & $45.1 \pm 17.9$ & $37.7 \pm 16.7$ & $0.004^{*}$ \\
\hline Bodily Pain & $55.8 \pm 18.9$ & $38.8 \pm 13.7$ & $0.001^{* *}$ \\
\hline General Health Status & $42.9 \pm 8.6$ & $40.7 \pm 6.5$ & $0.048^{*}$ \\
\hline Vitality & $61.6 \pm 11.3$ & $58.7 \pm 8.7$ & 0.057 \\
\hline Social Aspects & & $67.5 \pm 15.3$ & 0.123 \\
\hline Emotional Aspects & $71.3 \pm 18.3$ & $55.7 \pm 18.4$ & 0.39 \\
\hline Mental Health & $58.3 \pm 21.4$ & $70.3 \pm 7.4$ & $0.029^{*}$ \\
\hline
\end{tabular}

$\mathrm{p}<0.001 * *, \mathrm{p}<0.01 *$

Journal of Experimental Biology and Agricultural Sciences http://www.jebas.org 
Table 5 Comparison of pain intensity between gender

\begin{tabular}{c|ccc}
\multicolumn{1}{c|}{ Pain Intensity } & Male $(\mathrm{n}=91)$ & Female $(\mathrm{n}=95)$ & Significant value \\
& Mean \pm SD & Mean \pm SD & \\
\hline VAS & $48.6 \pm 16.2$ & $55.6 \pm 12.9$ & $0.001 * *$ \\
$\mathrm{p}<0.001 * *$ & & &
\end{tabular}

Table 6 Relationship between physical activity with pain intensity and quality of life

\begin{tabular}{lcc}
\multicolumn{1}{c}{ Variables } & Correlation coefficient & Significant value \\
& $\boldsymbol{r}$ & $\mathbf{p}$ \\
Physical activity - Pain intensity & & $<\mathbf{0 . 0 0 1} * *$ \\
VAS & -0.777 & \\
Physical activity - QOL & & $<\mathbf{0 . 0 1}^{* * *}$ \\
Functional Capacity & 0.639 & $<\mathbf{0 0 1} * *$ \\
Functional Limitation & 0.401 & $<\mathbf{0 . 0 0 1} * *$ \\
Bodily Pain & 0.652 & $<\mathbf{0 0 1} * *$ \\
General Health Status & 0.279 & $<\mathbf{0 0 1} * *$ \\
Vitality & 0.257 & $<\mathbf{0 0 1} * *$ \\
Social Aspects & 0.312 & $<\mathbf{0 . 0 0 1} * *$ \\
Emotional Aspects & 0.241 & $<\mathbf{0 0 1 * *}$ \\
Mental Health & 0.234 & \\
\hline
\end{tabular}

$\mathrm{p}<0.001^{* *}$

\subsection{Severity of pain in Knee Osteoarthritis}

In terms of severity of pain, $65.6 \%$ of participants presented with moderate pain (between 5 to 7 ), followed by $28.0 \%$ of them with mild pain (between 1 to 4 ), and $6.5 \%$ complaints of severe pain (between 8 to 10). There was a statistically significant difference in pain intensity observed, $p<0.001$ between genders as showed in table 5. Analysis of mean revealed a greater intensity of pain reported by females compared to males.

\subsection{Relationship between physical activity and other parameters}

The relationships between the level of physical activity with pain intensity and QOL was analyzed using Pearson's correlation as depicted in table 6 . between gender in participants who did not accomplish WHO recommendations for health $(\mathrm{p}=0.150)$. A strong negative correlation exists between level of physical activity and pain, which was statistically significant $(r=-0.777, n=186, p<0.001)$. This indicates that with increase physical activity level, there is reduce in pain intensity. In terms of the relationship between physical activity and QOL, a weak correlation exists for all the domains except functional capacity and body pain which demonstrate a moderate positive correlation.

\section{Discussion}

The current study aimed to determine the influence of gender on pain, quality of life, and physical activity among adults with knee osteoarthritis. The research findings indicate that the prevalence of 
knee osteoarthritis was greater in females as compared to males. osteoarthritis.

Similarly, previous studies have supported that females are at greater risk of osteoarthritis (Sowers et al., 2000; Srikanth et al., 2005; Hame \& Alexander, 2013; Prieto-Alhambra et al., 2014; Ferre et al., 2019). This can be due to lower pain threshold and less tolerance to painful stimuli by females as compared to males (Chesterton et al. 2003; Riley et al. 1998). In addition to this, reduce in estrogen production due to menopausal changes can further accelerate the process of degeneration (Hame \& Alexander, 2013). An earlier study has also documented an increased progression of cartilage degeneration and significant loss of tibial and patella cartilage in females than males (Eyre, 2004; Hanna et al., 2009). It has been reported that the rate of loss of cartilage at the tibia and patella in females is three to four times higher than in males (Hanna et al., 2009). Such findings show that females are more predisposed to osteoarthritis in the knee.

Results of the current study suggested that the highest percentage of participants were between the age of 50 to 59 years and with age beyond 60 years there is decreased in the incidence of osteoarthritis. A similar trend was also observed in the previous study (Prieto-Alhambra et al., 2014). Osteoarthritis progress rapidly in females during menopause aged between 55 to 60 years and gradually decline in the elderly. While for males, the incidence of osteoarthritis has increased gradually until the last stage of life (Prieto-Alhambra et al., 2014).

In terms of physical activity, the present study demonstrated that most of our participant did not achieve the guidelines for physical activity suggested by the World Health Organization (WHO) which is a minimum of 150 minutes of moderate-intensity of physical activity per week or 75 minutes of vigorous intensity of physical activity per week achieving 600 MET-min per week. It is notable, that the prescribed amount of physical exercise was not reached by a large percentage of participants and the incidence of knee osteoarthritis increases with age.

The outcome of the present study was further strengthened by previous studies which found females are insufficiently active in comparison with males (Troiano et al. 2008; Hamrik et al. 2014; Sparling et al. 2015). Factors that hinder the patient with knee osteoarthritis involve physical activity is not due to the onset of disease or pain but due to external factors such as time constraints and non-prioritization of physical activity (Mesci et al., 2015). In other cases, pain related fear has also contributed to immobility in a later stage, leading to inactivity (Steultjens et al., 2002). It is important to maintain regular physical activity to minimize and prevent functional and mobility-related disability and reducing the like hood of developing severe cardiovascular disease, metabolic disorder, perception deficit, osteoporosis, and muscle weakness (Rosenberg et al., 2011; McPhee et al. 2016; Chen et al., 2017).

The present study revealed that patients with knee osteoarthritis have overall impaired QOL primarily in the functional limitation domain. Similar results were obtained in a previous study which demonstrated patients with knee osteoarthritis had a significantly poorer quality of life (Salaffi et al., 2005). Besides that, physical health components showed significantly lower scores than the mental health component in the present study. This was consistent with other studies that reported the subscales related to physical health had relatively lower scores compared with the components of mental health (Lam \& Lauder, 2000; Zakaria et al. 2009). Our study also demonstrated statistically significant difference in functional capacity, $\mathrm{p}=0.019$, functional limitation, $\mathrm{p}=0.004$, bodily pain, $\mathrm{p}<0.001$, general health status 0.048 and mental health, $p=0.029$. Examination of the mean scores indicates that there was a greater quality of life for all the variables in males as compared to the females. The gender disparity in influencing the quality of life could be due to mechanical, environmental, and psychosocial factors such as employment, education, physical activity, muscle power, and pain coping skills (Rapp et al. 2000; Adamson et al. 2003; Dunlop et al. 2005).

In the present study, we noted that almost $65.6 \%$ of participants with knee osteoarthritis complain of pain. Pain is the hallmark symptom of osteoarthritis which limits the function and reduces the QOL (Dominick et al. 2004; Ayis \& Dieppe, 2009; Neogi 2013). It is the important precursor of physical disability and key symptom that influences the decision making of the patient with knee osteoarthritis in seeking medical treatment (Neogi, 2013). The findings of this study also suggest a remarkable difference between gender in pain perception $(p<0.001)$. Such results were comparable to prior research with women experiencing greater pain than men owning to lower pain threshold and tolerance to painful stimuli (Riley et al.,1998; Keefe et al., 2000; Chesterton et al., 2003; Tonelli et al., 2011). Present study findings can have significant implications for clinicians in treating pain. Clinicians might need to be aware that treatments may have different effects on pain perception when treating women versus men with knee osteoarthritis (Keefe et al., 2000).

In regards to the relationship between the QOL, pain, and level of physical activity the present study demonstrates a low positive correlation between QOL and physical activity in knee osteoarthritis patients. Current results were found to be consistent with the systemic reviews which have shown the positive correlation between regular physical activity and health-related QOL (Bize et al., 2007; Klavestrand \& Vingard, 2009). In terms of the relationship between pain and physical activity, the present study reported a strong, negative correlation between pain and 
physical activity, which indicates that with increase physical activity level, there is reduce in pain intensity. These results were similar to a study done by Wilkie et al. (2007) which reveals a strong association of knee pain with restricted mobility outside the home. Inactive patients were avoiding some movements or activities due to fear of pain although there was no real physical cause of pain over their knees (Steultjens et al., 2002). Hence, patients with knee osteoarthritis may develop progressive loss of physical function, the decline in QOL, and became dependent on their ADL (Loza et al., 2009).

\section{Conclusion}

In summary, present study reports greater numbers of female participants with knee osteoarthritis have relatively poor physical activity and quality of life and increase pain intensity as compared to males. This highlights the needs of clinicians to be aware of the gender influences in managing patients with knee osteoarthritis.

\section{Acknowledgements}

The authors like to thank all the participants for their voluntary participation in this study.

\section{Conflict Of Interest}

The author(s) declare(s) that there is no conflict of interest.

\section{Funding}

No funding was received for this study.

\section{References}

Adamson J, Hunt K, Ebrahim S (2003) Socioeconomic position, occupational exposures, and gender: the relation with locomotor disability in early old age. Journal of Epidemiology \& Community Health 57(6): 453-455.

Alenazi AM, Alshehri MM, Alothman S, Alqahtani BA, Rucker J, Sharma N, Segal NA, Bindawas SM, Kluding PM (2020) The Association of Diabetes with Knee Pain Severity and Distribution in people with Knee osteoarthritis using Data from the osteoarthritis initiative. Scientific Reports 10(1): 1-8.

Alkan BM, Fidan F, Tosun A, Ardıçoğlu Ö (2014) Quality of life and self-reported disability in patients with knee osteoarthritis. Modern Rheumatology 24(1): 166-171.

Ayis S, Dieppe P (2009) The natural history of disability and its determinants in adults with lower limb musculoskeletal pain. The Journal of Rheumatology 36(3): 583-591.
Bize R, Johnson JA, Plotnikoff RC (2007) Physical activity level and health-related quality of life in the general adult population: a systematic review. Preventive Medicine 45(6): 401-415.

Bull FC, Maslin TS, Armstrong T (2009) Global physical activity questionnaire (GPAQ): nine country reliability and validity study. Journal of Physical Activity and Health 6(6): 790-804.

Boutron I, Rannou F, Jardinaud-Lopez M, Meric G, Revel M, Poiraudeau S (2008) Disability and quality of life of patients with knee or hip osteoarthritis in the primary care setting and factors associated with general practitioners' indication for prosthetic replacement within 1 year. Osteoarthritis and Cartilage 16(9): 1024-1031.

Chen D, Shen J, Zhao W, Wang T, Han L, Hamilton JL, Im HJ (2017) Osteoarthritis: toward a comprehensive understanding of pathological mechanism. Bone Research 5(1): 1- 13.

Chesterton LS, Barlas P, Foster NE, Baxter GD, Wright CC (2003) Gender differences in pressure pain threshold in healthy humans. Pain 101(3): 259-266.

Chinese Orthopaedic Association (2010) Diagnosis and treatment of osteoarthritis. Orthopaedic Surgery 2(1): 1.

Crichton N (2001) Visual analogue scale (VAS). Journal of Clinical Nursing 10(5): 706-6.

Dekker J, van Dijk GM, Veenhof C (2009). Risk factors for functional decline in osteoarthritis of the hip or knee. Current Opinion in Rheumatology 21(5): 520-524.

Dillon CF, Rasch EK, Gu Q, Hirsch R (2006) Prevalence of knee osteoarthritis in the United States: arthritis data from the Third National Health and Nutrition Examination Survey1991-94. The Journal of Rheumatology 33(11): 2271-2279.

Dominick KL, Ahern FM, Gold CH, Heller DA (2004) Health related quality of life and health service use among older adults with osteoarthritis. Arthritis Care \& Research 51(3): 326331.

Dunlop DD, Semanik P, Song J, Manheim LM, Shih V, Chang RW (2005) Risk factors for functional decline in older adults with arthritis. Arthritis \& Rheumatism 52(4): 1274-1282.

Dunlop DD, Semanik P, Song J, Sharma L, Nevitt M, Jackson R, Osteoarthritis Initiative Investigators (2010) Moving to maintain function in knee osteoarthritis: evidence from the osteoarthritis initiative. Archives of Physical Medicine and Rehabilitation 91(5): 714-721. 
Elliott AL, Kraus VB, Fang F, Renner JB, Schwartz TA, Salazar A, Jordan JM (2007) Joint-specific hand symptoms and selfreported and performance-based functional status in AfricanAmericans and Caucasians: The Johnston County Osteoarthritis Project. Annals of the rheumatic diseases 66(12): 1622-1626.

Elizabeth W, Rena C (2011) The impact of osteoarthritis on psychological wellbeing. British Journal of Nursing 20(4): 243246.

Eyre DR (2004) Collagens and cartilage matrix homeostasis. Clinical Orthopaedics and Related Research 427: S118-S122.

Ferre IM, Roof MA, Anoushiravani AA, Wasterlain AS, Lajam CM (2019) Understanding the observed sex discrepancy in the prevalence of osteoarthritis. The Journal of Bone and Joint Surgery 7(9): e8.

Hame SL, Alexander RA (2013) Knee osteoarthritis in women. Current Reviews in Musculoskeletal Medicine 6(2): 182-187.

Hamrik Z, Sigmundová D, Kalman M, Pavelka J, Sigmund E (2014) Physical activity and sedentary behaviour in Czech adults: results from the GPAQ study. European journal of sport science 14(2): 193-198.

Hanna FS, Teichtahl AJ, Wluka AE, Wang Y, Urquhart DM, English DR, Giles GG, Cicuttini FM (2009) Women have increased rates of cartilage loss and progression of cartilage defects at the knee than men: a gender study of adults without clinical knee osteoarthritis. Menopause 16(4): 666-670.

Herrmann SD, Heumann KJ, Der Ananian CA, Ainsworth BE (2013) Validity and reliability of the global physical activity questionnaire (GPAQ). Measurement in Physical Education and Exercise Science 17(3): 221-235.

Heyland DK, Hopman W, Coo H, Tranmer J, McColl MA (2000) Long-term health-related quality of life in survivors of sepsis. Short Form 36: a valid and reliable measure of health-related quality of life. Critical care medicine 28(11): 3599-3605.

Kahl C, Cleland JA (2005) Visual analogue scale, numeric pain rating scale and the McGill Pain Questionnaire: an overview of psychometric properties. Physical Therapy Reviews 10(2): 123128.

Keefe FJ, Lefebvre JC, Egert JR, Affleck G, Sullivan MJ, Caldwell DS (2000) The relationship of gender to pain, pain behavior and disability in osteoarthritis patients: the role of catastrophizing. Pain 87(3): 325-334.
Klavestrand J, Vingård E (2009) Retracted: The relationship between physical activity and health related quality of life: A systematic review of current evidence. Scandinavian Journal of Medicine \& Science in Sports 19(3): 300-312.

Lam CL, Lauder IJ (2000) The impact of chronic diseases on the health-related quality of life (HRQOL) of Chinese patients in primary care. Family Practice 17(2): 159-166.

Loza E, Lopez Gomez JM, Abasolo L, Maese J, Carmona L, Batlle Gualda E, Artrocad Study Group (2009) Economic burden of knee and hip osteoarthritis in Spain. Arthritis Care \& Research 61(2): 158-165.

McPhee JS, French DP, Jackson D, Nazroo J, Pendleton N, Degens $\mathrm{H}$ (2016) Physical activity in older age: perspectives for healthy ageing and frailty. Biogerontology 17(3): 567-580.

Mesci E, Icagasioglu A, Mesci N, Turgut ST (2015). Relation of physical activity level with quality of life, sleep and depression in patients with knee osteoarthritis. Northern clinics of Istanbul 2(3): 215 .

Neogi T (2013) The epidemiology and impact of pain in osteoarthritis. Osteoarthritis and Cartilage 21(9): 1145-1153.

Prieto-Alhambra D, Judge A, Javaid MK, Cooper C, Diez-Perez A, Arden NK (2014) Incidence and risk factors for clinically diagnosed knee, hip and hand osteoarthritis: influences of age, gender and osteoarthritis affecting other joints. Annals of the Rheumatic Diseases 73(9): 1659-1664.

Primorac D, Molnar V, Rod E, Jeleč Ž, Čukelj F, Matišić V, Vrdoljak T, Hudetz D, Hajsok H, Borić I (2020) Knee Osteoarthritis: A Review of Pathogenesis and State-Of-The-Art Non-Operative Therapeutic Considerations. Genes 11(8): 854.

Rapp SR, Rejeski WJ, Miller ME (2000). Physical function among older adults with knee pain: the role of pain coping skills. Arthritis Care \& Research 13(5): 270-279.

Riley III JL, Robinson ME, Wise EA, Myers CD, Fillingim RB (1998) Sex differences in the perception of noxious experimental stimuli: a meta-analysis. Pain 74(2-3): 181-187.

Rosenberg DE, Bombardier CH, Hoffman JM, Belza B (2011) Physical activity among persons aging with mobility disabilities: shaping a research agenda. Journal of Aging Research, 2011:708510.

Salaffi F, Carotti M, Stancati A, Grassi W (2005) Health-related quality of life in older adults with symptomatic hip and knee 
osteoarthritis: a comparison with matched healthy controls. Aging Clinical and Experimental Research 17(4): 255-263.

Sharma A, Kudesia P, Shi Q, Gandhi R (2016) Anxiety and depression in patients with osteoarthritis: impact and management challenges. Open access Rheumatology: Research and Reviews 8: $103-113$.

Somers TJ, Keefe FJ, Pells JJ, Dixon KE, Waters SJ, Riordan PA, Blumenthal JA, McKee DC, LaCaille L, Tucker JM, Schmitt D (2009) Pain catastrophizing and pain-related fear in osteoarthritis patients: relationships to pain and disability. Journal of Pain and Symptom Management 37(5): 863-872.

Sowers M, Lachance L, Hochberg M, Jamadar D (2000) Radiographically defined osteoarthritis of the hand and knee in young and middle-aged African American and Caucasian women. Osteoarthritis and Cartilage 8(2): 69-77.

Sparling PB, Howard BJ, Dunstan DW, Owen N (2015) Recommendations for physical activity in older adults. British Medical Journal 350: h100

Srikanth VK, Fryer JL, Zhai G, Winzenberg TM, Hosmer D, Jones G (2005) A meta-analysis of sex differences prevalence, incidence and severity of osteoarthritis. Osteoarthritis and Cartilage 13(9): 769-781.

Steultjens MPM, Dekker J, Bijlsma JWJ (2002) Avoidance of activity and disability in patients with osteoarthritis of the knee: the mediating role of muscle strength. Arthritis \&Rheumatism: Official Journal of the American College of Rheumatology 46(7): 1784-1788.
Tonelli SM, Rakel BA, Cooper NA, Angstom WL, Sluka KA (2011) Women with knee osteoarthritis have more pain and poorer function than men, but similar physical activity prior to total knee replacement. Biology of Sex Differences 2(1): 12.

Troiano RP, Berrigan D, Dodd KW, Masse LC, Tilert T, McDowell M (2008) Physical activity in the United States measured by accelerometer. Medicine and science in sports and exercise 40(1): 181.

Ware Jr, John E (2000) SF-36 health survey update. Spine 25(24): 3130-3139.

Wilkie R, Peat G, Thomas E, Croft P (2007) Factors associated with restricted mobility outside the home in community dwelling adults ages fifty years and older with knee pain: an example of use of the international classification of functioning to investigate participation restriction. Arthritis Care \& Research 57(8): 13811389.

Yildiz N, Topuz O, Gungen GO, Deniz S, Alkan H, Ardic F (2010) Health-related quality of life (Nottingham Health Profile) in knee osteoarthritis: correlation with clinical variables and self-reported disability. Rheumatology International 30(12): 1595-1600.

Zakaria ZF, Bakar AA, Hasmoni HM, Rani FA, Kadir SA (2009). Health-related quality of life in patients with knee osteoarthritis attending two primary care clinics in Malaysia: a cross-sectional study. Asia Pacific Family Medicine 8(1): 1-7. 